\section{THE FULL SPECTRUM OF FULLY INTEGRATED CHAIRS}

A-dec looks forward to welcoming you to stand M03 at this year's BDIA Dental Showcase.

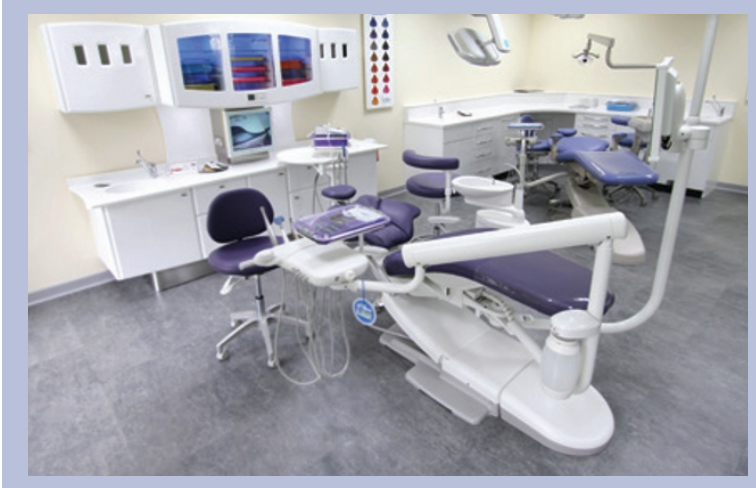

This year A-dec will be showcasing the full spectrum of fully integrated dental chairs with cabinetry solutions from the current range. Whatever your budget, there is an A-dec chair for you, from the newest entry level package, the Performer LR+, right up to the luxurious A-dec 500 chair. All of A-dec's dental chairs can be tailored to your specification to give you everything you need.

Also on stand M03 this year
A-dec will be presenting their difference display which shows a selection of the high quality A-dec parts that go into every chair. In addition we will be bringing back the popular consultation area, where we will be offering design and equipment advice and even drawing up your surgery plans live on the stand.

The A-dec Territory Managers will be on stand for the duration of the show. Visit them on stand M03 or call 0800233285 for more information. www.a-dec.co.uk

\title{
A BETTER WAY TO BATTLE BIOFILM
}

CleanCert, a new biofilm cleaner for dental unit water systems offering unbeatable reliability, safety, economy and ease of use, has recently been launched in the UK. The product's active ingredient has been successfully used at over 35 NHS Trusts for more than a decade and independent research proves that after five minutes' contact time, CleanCert achieves the highest score possible (0 CFU) in eliminating all patho-
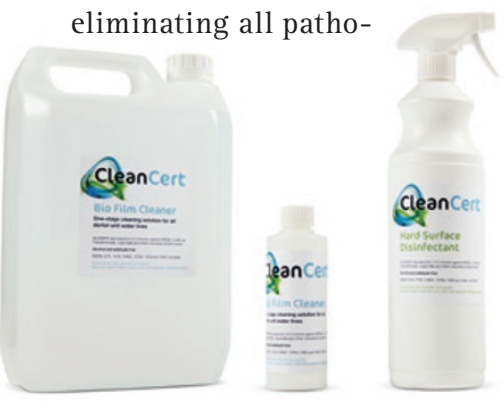

gens that could cause a build-up of biofilm.

Other biofilm cleaners involve time and hassle. They need corrosive pre-treatments using peracetic acid, or involve complicated mixing formulas and require you to leave the solution in the chair's waterlines overnight. With CleanCert, you simply pour in $200 \mathrm{ml}$, leave for a five minute contact time and rinse for ten seconds - easy, 100\% effective and considerably cheaper on a weekly basis than the market leader. Don't worry about skin contact: CleanCert has the one of the most user and environmentally friendly disinfectants on the market.

CleanCert is available through The Dental Directory and Quintess Denta as a biofilm cleaner for dental unit water systems $(2.5 \mathrm{~L}$ and $5 \mathrm{~L}$ ) and as a hard surface 'all-in-1' disinfectant spray for eliminating pathogens (MRSA, C. difficile, HIV etc) on all working surfaces in the dental surgery (1 litre).

For more information, email sales@ cleancert.co.uk or call 08443511115.

\section{TOOTH WHITENING STRIPS THAT DISSOLVE IN THE MOUTH}

WhiteWash Laboratories will be on hand at this year's BDIA Dental Showcase to show delegates exactly why their professional whitening products have become so sought-after.

New for this year from WhiteWash Laboratories are innovative and flexible trays specially designed to maximise comfort. The surface material replicates enamel and prevents the gel from coming into contact with saliva, so the whitening results last longer.

Other up-and-coming products include electric toothbrushes and dissolving whitening strips. Giving fantastic results, the whitening strips dissolve on their own after 15 minutes for maximum patient comfort.
Visitors to the stand can also learn about WhiteWash's 'Brush for a Brush' campaign. Working with UK primary schools and overseas charities, WhiteWash will donate a brush or toothpaste for every product bought. WhiteWash is also helping to raise awareness of breast and prostate cancer with its funky pink and black toothbrushes.

For more information call 0844 6869150 or visit www.whitewashlaboratories.com.

\section{LOOKS LIKE A FLOWABLE, BEHAVES LIKE A RESTORATIVE}

$\mathrm{GC}$ is well known for their exceptionally innovative materials including MI Varnish with RECALDENT. Remaining on the teeth longer and containing high levels of fluoride and calcium MI Varnish is ideal for patients at risk of hypersensitivity.

Children with fragile, erupting teeth need effective protection fast. Fluoride-releasing Fuji Triage already has a strong track record of preventing caries in erupting teeth. This self-adhesive material is insensitive to moisture and has a low enough viscosity to penetrate pits and fissures, making it truly effective. Fuji Triage Dentonauts leaflets simply explain the benefits of protecting vulnerable teeth to your patients.

Gaenial Universal Flo from GC is a high wear injectable composite for general restorative use comprising a unique filler technology. This restorative material features a high filler load and a homogeneous dispersion of fillers, resulting in high strength and great wear resistance. Being radiopaque and highly viscous makes it ideal for placement in Class I-V restorations. Essentially, it looks like a flowable but behaves like a restorative.

For further information visit GC UK on stand H02 or call 01908 218999. 